\title{
GIRLFRIENDS, SEX AND VIOLENCE: THE ATTITUDES AND REPORTED BEHAVIOURS OF ADOLESCENT MALES IN A SOUTH AFRICAN TOWNSHIP
}

\section{Maroyi Mulumeoderhwa, Geoff Harris}

\section{INTRODUCTION}

It has long been recognised that levels of gender violence in contemporary South Africa are very high and that a significant part of this violence involves forced sex. The Centre for the Study of Violence and Reconciliation (CSVR) (2008) has characterised the country as being in a "state of sexual tyranny". The specific aim of this research is to better understand the important beliefs and attitudes of a sample of young urban men concerning girlfriends, violence and sex. Such beliefs and attitudes are likely to result in behaviours which have direct implications for the high levels of gender violence, the high rates of HIV prevalence and the incidence of new infections.

There have been two distinct approaches to the study of male violence towards women. Until quite recently these studies have been predominantly quantitative and have focused on the incidence of male violence and its effects on women. For example, among 1306 randomly selected women aged 18-49 years from the Eastern Cape, Mpumalanga and Northern Provinces who were interviewed in 1998, 24.6\% had experienced physical abuse and $9.5 \%$ had experienced it within the last year. Of the latter, $45.9 \%$ reported being physically injured as a result (Jewkes, Levin \& Penn-Kekana, 2002).

However, there has been a recent shift towards studying the attitudes and behaviour of the male perpetrators of this violence. Jewkes, Sikweyiya, Morrell and Dunkle (2009) found that $27.6 \%$ of a nationally-representative survey of 1738 African males in KwaZulu-Natal and the Eastern Cape said that they had raped a woman or girl, and that $4.6 \%$ said they had done so within the last year. Some $42 \%$ said that they had been physically violent to an intimate partner, and $14 \%$ said that this had occurred within the last year.

The interface between violence and adolescent sexual health has increasingly become the subject of academic study in Africa and the research in this area has been largely focused on young women. Again, there has been a recent trend to investigate the masculinities involved in this violence by studying the attitudes and behaviour of young men in order to understand the reasons behind gender violence (Morrell, 2005; Sathiparsad, 2005, 2006; Sathiparsad \& Taylor, 2006; Varga, 2001, 2003). This research on masculinities has been largely qualitative, involving focus groups and in-depth interviews with small numbers of participants.

Sathiparsad's research with Grade 11 male students in rural KwaZulu-Natal used similar data-collection methods to those of the present study. Her focus groups were designed to reveal broad perceptions of masculinity, while the follow-up personal interviews sought information on the individual participants' attitudes and behaviour. Her findings can be summarised as follows: men have the dominant role in male-female relationships; they 
cannot control their sexual desires and it is women's role to satisfy men's sexual needs; forced sex is completely acceptable within marriage and also with girlfriends; physical violence by men against women is acceptable if, for example, a woman shows excessive assertiveness, is disobedient or refuses to have sex; and multiple sexual partners for men is acceptable. While these views were held by around three quarters of her participants, there were some who held an alternative view which emphasised more equitable gender roles.

The focus of this article is on the beliefs and attitudes held by young men in an urban township and their influence on reported sexual behaviour. The findings of Sathiparsad and associates are case studies from one rural area of KwaZulu-Natal and cannot be generalised to a wider population. It is interesting to note that Sathiparsad has made a number of presentations of her findings to audiences of young Zulu males and females and reports their general agreement with her findings (Personal communication, 10 July 2010). She has recommended that more case studies need to be carried out so that the wider validity of her findings can be assessed. That is, if a number of case studies come up with similar results, it is more likely that some general phenomena are being identified. This article reports such a case study in an urban township of KwaZulu-Natal.

\section{RESEARCH PROBLEM}

We are aware that a major aspect of violence in South Africa is that it is committed by men against women with whom they are in a relationship. The discipline of peace studies recognises that conflict arises from the different needs and wants of individuals and is therefore inevitable; committing violence, on the other hand, is a choice. We are motivated to help build relationships which are characterised by non-violent ways of dealing with conflict and by respect for the other person. Understanding the underlying causes of male violence towards women is a necessary step towards changing male behaviour for the better. Accordingly, this research attempts to uncover the beliefs and attitudes of young men towards young women with whom they have a relationship. This is undertaken in the light of the findings of the most comprehensive report on sexual violence in South Africa (Centre for the Study of Violence and Reconciliation, 2008), which identifies three main causes of such violence - beliefs concerning male sexual entitlement, feelings of insecurity in males and the context of a violent society. The first of these is directly related to our research.

\section{RESEARCH METHODS}

The study took place at one high school of around 900 learners located in KwaMashu, one of the largest of the African townships established in Durban under apartheid with a population of close to one million. The school is fairly typical of township high schools in Durban in terms of size and the socio-economic background of its learners. The Grade 11 and 12 male learners who participated in the study as representative of this group of learners in the school were selected by the school's principal and one teacher. This selection process, over which we had no control, cannot be regarded in any sense as random, but our impression is that the responses of the students in the sample were fairly typical of those held by the Grade 11 and 12 male learners. 
Given that neither of the authors speaks fluent isiZulu, data collection was carried out by a young Zulu male university undergraduate who was carefully trained by the first author. This training focused on the translation of the interview schedules into isiZulu during which the reasons underlying each question were discussed in detail. This was also done in the de-briefing sessions which followed each focus group and during each of the three days during which individual interviews were carried out. The data were collected during May 2009. Two semi-structured focus group interviews were organised, each lasting about one hour. One comprised seven learners aged 15-17 years and the other of seven 18- to 20-year-olds; in the event, no important differences were detected between the age groups. The focus groups were supplemented by semi-structured individual interviews with each of the focus group participants to follow up issues on a personal basis. In both cases the research assistant was instructed to allow the responses to come to an apparent end before moving on to the next question. Responses were tape recorded (with the permission of the learners), transcribed into isiZulu and then translated into English for subsequent analysis.

The particular benefit of focus groups derives from the interaction, discussion and debate among the participants. It is a more natural environment than an interview in that participants are influencing others and being influenced by them - just as they are in real life. The moderator plays a low key role and feeds in a limited number of questions at appropriate times.

The questions asked during the focus groups were as follows:

- Can men abstain from sex?

- Is it OK for a girlfriend or wife to say no to sex on any particular occasion?

- Is it OK to force a wife or girlfriend to have sex with you?

- Is it OK to have more than one girlfriend at a time?

- Is it important to use condoms?

Focus group participants differ in terms of the extent, insight and forcefulness of their verbal contributions and we were alert to the possibility that a dominant individual might direct a focus group in a direction at variance with the views of the majority. The use of direct quotations from informants is one way of guarding against this, as were follow-up meetings in the form of interviews. The interviews allowed us to personalise the issues raised in the focus groups. For example, for the third focus group question, the related interview question was: "Would you force your wife or girlfriend to have sex?"

Ethical clearance for the project was granted by the relevant University of KwaZuluNatal committee and by the KwaZulu-Natal Department of Education and Culture. The nature of the research was explained to learners and it was made clear that their contribution was entirely voluntary; in the event, there were no refusals and participants were very engaged during the focus groups and interviews. Parental permission was obtained for participants under the age of 18 . For reasons of confidentiality, the school is not named in this article and respondents are given pseudonyms. 


\section{DATA ANALYSIS}

Our method of analysis has been described as "interpretative thematic analysis" (Hsieh \& Shannon, 2005; Parker \& Tritter, 2006; Vicsek, 2007). That is, by an intensive reading of the focus group and interview transcripts, we sought to identify the beliefs and attitudes held by the informants. This method contains the risk that a researcher may deliberately or unwittingly inject his/her own biases into the results and reach inaccurate conclusions; that is, it may fail in terms of internal validity. We attempted to guard against this in several ways: by utilising the findings and research methods of previous studies; by employing a young male isiZulu speaker to conduct the data collection; by using semi-structured interviews in part to check the findings of the focus groups; and by involving two authors in the preparation of the article, both of whom were very aware of the possibility of bias. In the process of preparing the article, we had a number of discussions concerning the beliefs and attitudes which emerged under each theme. We believe that if outsiders were to analyse our data, they would identify similar themes and reach similar conclusions.

The themes we identified arose largely from the questions asked during the focus groups and individual interviews, which in turn arose from our research objective and the previous research whose findings we were trying to verify. We identified two general themes from the learners' responses - concerning sexual abstinence and forced sex plus another two of particular importance in the context of HIV/AIDS - multiple sexual partners and the use of condoms. The quotations we present are, unless otherwise noted, representative of the views of the majority of participants as expressed in both the focus groups and interviews.

\section{RESULTS AND DISCUSSION}

\section{Theme 1: Peer pressure makes sexual abstinence or restraint a difficult option}

The focus groups were asked whether it was possible for men to abstain from sex or at least restrain themselves until they were married or in a committed relationship. The answers were clear and strong: men are made to have sex and waiting is not an option.

"I don't agree that we should wait till we married, I am a guy and I have feelings and needs ... Sometime some girls are going for virginity testing, so it's best to wait until she is ready. But hey, you can have another girl on the side though, while you wait [everybody laughs]. I mean we are guys and we have feelings and needs, I am telling the truth." (Thando)

"No, no I can't wait. There are quick bites out there as we all know. I can't wait." (Andile)

\section{"I agree [with Andile], I can't wait." (Nhlaka)}

"When I am in a relationship with a woman, I expect sex." (Coke)

The interviews provided an opportunity to probe this strongly held belief. There was some comment to the effect that men cannot control their sexual urges, but this was 
moderated (for example, by Thando) by remarks that there is no need to abstain because other sexual partners are readily available (see also Theme 3 below). Some interviewees were clear that "a relationship means sex" (for example, Coke), although later discussion, as we shall see, revealed that not all girlfriends were sexual partners. Only one of the participants (Njabulo) expressed a different opinion: "For me, it's not that I am waiting as such, but to be honest I am scared of HIV/AIDS" [laughter in the room], implying that abstinence is a possibility. Earlier studies reported stronger evidence that South African men are socialised into thinking that they cannot control themselves sexually (Sathiparsad, 2005, 2006; Varga, 2003).

Further focus group discussion showed that waiting is possible and even a good thing (Joe), but that peer pressure makes it very hard for young men to have a relationship without sex. This links with current Zulu attitudes concerning what it means to be a man (see Theme 3).

"Waiting is good, but due to peer pressure you end up not being able to wait. Because guys are laughing at you and saying you have not had sex yet." (Joe)

"I don't feel a relationship right now should have sex involved, but then peer pressure makes young people of my age engage in early sex. Boys laugh at other boys when they know that they don't have sex. And they bring in those myths that people who have not had sex are slower, and you start to see those signs on yourself." (Mario)

"Yes, I can have a relationship without sex, but peer pressure out there is big, guys ask things as to why do you keep an apple without eating it. So as a guy you might end trying to change your girl's mind to have sex with her." (Coke)

The interviews on this issue brought out the tension of believing one thing as an individual but practising something else because of the power of peer pressure and wider societal attitudes, a finding consistent with other research on adolescent males in Zimbabwe and South Africa (Pattman, 2007).

There is also a belief in the necessity of sexual intercourse for health reasons. As Halls remarked during a focus group, "I feel that people who don't have sex regularly are a bit not right upstairs. So until they release the sperm their mind will be clogged up " [noises of agreement from the group]. Most of the interviewees agreed with this sentiment, although they were not able to explain it in any detail during the interviews.

\section{Theme 2: It is OK to force a girlfriend to have sex}

The two main questions discussed in the focus groups on this issue were whether a girl has any right to refuse sex and, if she does refuse, whether it is justifiable for a man to use force to have sex. On the first, the participants were in general agreement that a girl with whom they were in a relationship cannot say no, at least not without a "good reason":

"Me, I would not let her go. Once we are in the room, my rules apply. She is wet, I am horny, so it means sex to me." (Andile) 
"According to me, she does not have a right to say no to sex, and if she does she must have a good reason that allows her to do so." (Joe)

"Girls do have a right to say no to sex, but they must not say no all the time; the following time she must have a good reason." (Nhlaka)

Several explanations were given for this position in the focus groups: one is that girls have, by their actions (for example, by entering a boy's bedroom), said yes; that they in fact mean yes even when they are saying no; and that a man who fails to get sex is a failure.

"Once she is in your bedroom, it's a yes. If he fails to make it, this means the guy has a problem.” (Thando)

"Some girls mean yes when they say no. Even though they say no heir bodies are responding with a yes, so all a guy has to do is put enough pressure till she says yes." (Mario)

"When a girl is in my room that means yes. She would not leave without giving me sex, but if she persists in saying no, I will not force myself on her." (Halls)

In addition to not meeting their sexual desires, men's egos are threatened if women refuse them. After all, they are in charge of male-female relationships. They will feel like failures and, as Thando and Joe pointed out during their interviews, it is also likely that the girl will then bad mouth them to others for having failed to convince them to have sex - because that is what they (women) really want. One study of South African school students (Andersson, Ho-Foster, Matthis, Marokoane, Mashiane, Mhatre, Mitchell, Mokoena, Monasta, Ngxowa, Salcedo and Sonnekus, 2004) found that over half of male students claimed that girls generally meant yes to sex when they said no. The majority of rural KwaZulu-Natal learners in Sathiparsad's (2005, 2006) study also held this view.

Given that waiting is a difficult option for men and that women do not have the right to refuse sex, if a man cannot convince a woman to comply, then forced sex is generally considered appropriate. This is supported by a belief that some women like forced sex.

"I agree some girls like forced sex, and even ask for it themselves at times." (Njabulo)

"In my experience, some girls like forced sex. They go even to a point to spread the rumours that they want particular guys to have rough sex with them." (Coke)

" $50 \%$ of women like it [forced sex] and some don't like it, and when you use force that turns some off." (Sifiso)

However, in the interviews some participants were clear that they would not force a girl to have sex:

"No means no. It does not matter how wet or ready she may seem, once she says no, you as a guy should stop because she knows why she says no." (Joe) 
"I tried it [forced sex] once but she cried and I stopped." (Halls)

To sum up: most of the participants believed that girls had no right to say no to sex without a good reason. Even when they did say no, they frequently meant yes and were, in Coke's words, "playing with guys". If they could not be persuaded with words, then the majority of participants approved of forced sex.

\section{Theme 3: Multiple concurrent sexual partners proves that you are a "real man"}

The basic question asked in the focus groups was "What do you think of a man having more than one sex partner?" Multiple sexual partners could be a number of sexual partners at any point of time or a sequence of sexual partners, but it was clear from their answers that the participants meant the former.

Representative comments in the focus groups were as follows:

"I think that all men are dogs and girls are dustbins. Dogs go through the bins and leave them open and the next dog does the same. Men are just dogs." (Njabulo)

"I think you can have one girlfriend, but at times the one person breaks your heart so I think sometimes it is OK to have more than one girlfriend. But when you decide to get married I think it is good to just have one person that you have chosen to be your wife for the rest of your life." (Mario)

"I think we should have more than one girlfriend. Even to sleep with one girlfriend for each day of the week." (Thando)

"I think too many girls in one's life spread AIDS. I think two is just fine." (Nhlaka)

While Thando holds the view that any number of sexual partners is acceptable for a man, Njabulo is critical of men sleeping around. Mario believes in the middle ground: it is fine for young men to have a number of partners in case one breaks your heart, but in marriage, men should be monogamous.

The interviews revealed why the majority of the sample supported Thando's opinion: having multiple sexual partners is the way a young man is recognised as a real man. This is supported by other studies. Hunter (2005) traces various historical precedents for Zulu men having multiple partners. He explains that young Zulu men in the 1940s and 1950s aspired to become an isoka, a single young man famous for his prowess in courting several women. Subsequently, he set up an independent household with several wives and was recognised as a real man. A turning point came in the 1970s, when economic constraints made it increasingly difficult to set up such households. Such constraints on the traditional way of becoming a man have resulted, in Hunter's view, in the current stress on multiple sexual partners.

In their study of Zambian university students, male peer pressure was identified as the most important factor influencing concurrent partners: "for many young men, masculinity was intimately related to [having] multiple sexual partners" (Nshindano \& 
Maharaj, 2008). Izugbara's (2004) study of rural Nigerian adolescent boys found that having multiple concurrent sexual partners was considered natural and proper for adolescent males, and proof that one was a real man.

In the interviews the number of girlfriends mentioned most commonly was two, with some suggestion that money was a limiting factor. A review of studies of South African youths between 1990 and 2000 (Eaton, Flisher \& Aaro, 2003) found that at least 50\% of young people were sexually active by the age of 16 years. Of those school students who had experienced sexual intercourse, the majority of reported one partner in the previous year, although 10-25\% of males reported having more than four sexual partners per year.

Not all a boy's girlfriends, it should be noted, may be sexual partners. When the interviewer asked participants about the number of girlfriends they had, their answers included the following:

"I have seven girlfriends. One is my age, and the others are younger than me. But I have not been to bed with any of them." (Ajex)

"I have many girlfriends, about seven or eight. Some are my age and others are younger. I don't go to bed with all of them but it does not matter which one I go to bed with." (Thando)

"I have four girlfriends, ranging from 13 to 18 years, I don't go to bed with all of them, just the ones who are 17 and 18 years." (Sizwe)

These responses imply that having a number of girlfriends could meet the participants' need to be recognised for their ability of courting women and acted as a sign of their sexual prowess. However, as the responses show, the number of girlfriends may exaggerate the number of sexually active relationships.

\section{Theme 4: Condom use is a man's decision}

In response to a question about their use of condoms, most of the participants were clear that the decision to use condoms was a male prerogative. Participants had a strong preference for "flesh-to-flesh" sex because condoms were said to reduce their sexual pleasure, an opinion reported in many studies (Versteeg \& Murray, 2008). However, several participants felt that the emphasis on flesh-to-flesh sex was based on talk rather than reality: "I think this flesh-to-flesh sex is due to a lot of peer pressure ... men are saying things like they don't eat sweets in a wrapper [have unprotected sex] just to impress each other" (Coke). That said, between 50 and 60\% of sexually active South African youths studied between 1990 and 2000 reported never using condoms (Eaton et al., 2003).

A sub-theme was that condoms are untrustworthy:

"I don't trust the condom it breaks and tears; it's just a white man's thing, a thing of this world. And condom does not protect at all." (Nhlaka)

"I think condoms are risky because they can break and get torn." (Mario) 
"I think they (condoms) are 50\% safe, I think they are more expensive and they are not safer. I prefer brown dash [sex without a condom], and I think the government condoms are the ones that burst the most." (Halls)

Participants were asked why they thought a girl might want a man to wear a condom. Most responses suggested that it reflected a lack of trust on the part of the girl, presumably (given the widespread practice of multiple sexual partners) about the boy's HIV status:

"I think she is protecting herself from becoming pregnant, and she may also be protecting me or that she does not trust me." (Joe)

"Maybe it would be because she does not trust me or that she thinks I am sick." (Sizwe)

"If a girl says we must use a condom, I think she knows that she has AIDS, and that she does not trust me. The reason I would ask why is because every time I have sex I expect the guy to be the one to suggest using a condom." (Tshepo)

More generously, Sifiso commented during his interview that "What comes in my mind is that she loves me and that she is protecting us from all the disease out there".

The male preference for sex without condoms was clearly recognised as contributing to the spread of HIV and suggests much greater understanding than among Sathiparsad's rural students. In Nkhala's words:

"Most of the times I think men are the ones who spread AIDS because they refuse to use condoms (saying I can't eat a sweet while it is wrapped up). And we as men have more than one girlfriend, when we will break up with some of them [girls] and they will start in new relationships, where the next man in their relationship will also refuse to use a condom. So AIDS spreads quickly."

\section{CONCLUSION}

The specific aim of this research was to understand the attitudes and reported behaviour of a small sample of young urban men concerning girlfriends, violence and sex in the context of HIV/AIDS. The findings of this case study in an urban township are consistent with previous studies pertaining to rural KwaZulu-Natal adolescent males. In particular, the young men felt that they cannot abstain from sex, that force is appropriate when a girlfriend is unwilling to engage in sex, and that having multiple concurrent sexual partners is normal and natural for men. These beliefs appear to be central to the ways in which masculinities are constructed for adolescent males in this urban context, although a minority expressed alternative viewpoints which gave women a more equal role in male-female relationships.

The main limitation of this study is that it is based on data from a small number of participants, although this is a common characteristic of qualitative research. As noted, this research was intended to add to the limited number of studies on the beliefs, attitudes and reported behaviours of adolescent males, rather than being a stand-alone piece of research. A further indication of its external validity is its consistency with 
historical and ethnographic research. We have already referred to Hunter's (2005) research on multiple sexual partners. Another example is the study (Wood, Lambert \& Jewkes, 2008) on an Xhosa urban township which concluded that:

"For young men, the importance of women to their sense of masculinity, both in terms of their own self-respect and esteem and in the eyes of others, was evident in the energy they expended on acquiring and maintaining desirable girlfriends, gaining sexual access to them ... and attempting to control their behaviour."

The third and fourth themes - strong support for multiple sexual partners and a strong mistrust of condoms - have particular relevance to the fight against HIV/AIDS. KwaZulu-Natal has the highest prevalence among the South African provinces, with $38.9 \%$ of ante-natal clients in 2008 utilising public health facilities because they were HIV positive. Young people are particularly at risk, with those aged 15-24 years accounting for $45 \%$ of all new infections in South Africa (Department of Health, 2009). Overall, our results cast doubt on the probable efficacy of the South African government's emphasis on the ABC (Abstain, Be faithful, Condomise) approach to HIV/AIDS prevention, given the way masculinities are currently understood and practised by male adolescents.

If policymakers hope to bring about desired behaviour change - towards less violent and more equitable male-female relationships - then they need to identify cost-effective interventions. The research reported here supports previous research that young adolescent males have beliefs and attitudes which often lead them to use violence in sexual relationships and to engage in sexual behaviours which are risky to themselves and to their sexual partners. Beliefs, attitudes and behaviour can change, but there are no quick fixes. A number of researchers (Sathiparsad, 2008; Sathiparsad, Taylor \& De Vries, 2010) have emphasised the centrality of educational interventions with young people in order to bring about more respectful gender relationships and safer sexual behaviours. There is recent evidence of some positive behaviour change among young people, particularly the greater use of condoms, in apparent response to a range of targeted interventions (Taylor, Dlamini, Meyer-Weitz, Sathiparsad, Jinabhai \& Esterhuizen, 2010).

\section{REFERENCES}

ANDERSSON, N., HO-FOSTER, A., MATTHIS, J., MAROKOANE, N., MASHIANE, V., MHATRE, S., MITCHELL, S., MOKOENA, T., MONASTA, L., NGXOWA, N., SALCEDO, M. \& SONNEKUS, H. 2004. National cross-sectional study of views on sexual violence and risk of HIV infection and AIDS among South African school pupils.

British Medical Journal, 329(7472):952-57.

CENTRE FOR THE STUDY OF VIOLENCE AND RECONCILIATION. 2008. A state of sexual tyranny. The prevalence, nature and causes of sexual violence in South Africa. Johannesburg: CSVR.

DEPARTMENT OF HEALTH. 2009. The national HIV and syphilis prevalence survey, South Africa 2008. Pretoria: National Department of Health. 
EATON, L., FLISHER, A. \& AAR Ø, L. 2003. Unsafe sexual behaviour in South African youth. Social Science and Medicine, 56(1):49-65.

HSIEH, H-F. \& SHANNON, S. 2005. Three approaches to qualitative content analysis. Qualitative Health Research, 15(9):1277-1288.

HUNTER, M. 2005. Cultural politics and masculinities: multiple partners in historical perspective in KwaZulu-Natal. Culture, Health and Sexuality, 7(4):398-403.

IZUGBARA, O. 2004. Notions of sex, sexuality and relationships among adolescent boys in rural southeastern Nigeria. Sex Education, 4(1):63-80.

JEWKES, R., LEVIN, J. \& PENN-KEKANA, L. 2002. Risk factors for domestic violence: findings from a South African cross-sectional study. Social Science and Medicine, 55(2):1603-1617.

JEWKES, R., LEVIN, J. \& PENN-KEKANA, L. 2003. Gender inequalities, intimate partner violence and HIV preventive practices: findings of a South African crosssectional study. Social Science and Medicine, 56(1):125-134.

JEWKES, R., SIKWEYIYA, Y., MORRELL, R. \& DUNKLE, K. 2009. Understanding men's health and use of violence: interface of rape and HIV in South Africa. Pretoria: Medical Research Council.

MORRELL, R. 2005. Men, movements and gender transformation in South Africa. In: OUZGANE, L. \& MORRELL, R. (eds) African masculinities: men in Africa from the late nineteenth century to the present. Scottsville, University of KwaZulu-Natal Press.

PARKER, A. \& TRITTER, J. 2006. Focus group method and methodology: current practice and recent debate. International Journal of Research and Method in Education, 29(1):23-37.

NSHINDANO, A. \& MAHARAJ, P. 2008. Reasons for multiple partnerships: perspectives of young people in Zambia. African Journal of AIDS Research, 7(1):3744.

PATTMAN, R. 2007. Researching and working with boys in southern Africa in the context of HIV/AIDS: a radical approach. In: SHEFER, T., RATELE, K., STREBEL, A., SHABALALA, N. \& BUIKEMA. R. (eds) From boys to men: social construction of masculinities in contemporary society. Cape Town: UCT Press.

SATHIPARSAD, R. 2005. 'It is better to beat her': male youth in rural KwaZulu-Natal speak on violence in relationships. Agenda, 66:79-88.

SATHIPARSAD, R. 2006. Gender violence and masculinity: a study of rural male youth. Durban: University of KwaZulu-Natal. (PhD thesis)

SATHIPARSAD, R. 2008. Developing alternative masculinities as a strategy to address gender-based violence. International Social Work, 51(3):348-359. 
SATHIPARSAD, R. \& TAYLOR, M. 2006. Diseases come from girls: perspectives of male learners in rural KwaZulu-Natal on HIV infection and AIDS. Journal of Education, 38(2):118-137.

SATHIPARSAD, R., TAYLOR, M. \& DE VRIES, H. 2010. Masculine identity and HIV prevention among male youth in rural South Africa. Journal of Social Sciences, 25(2):159-168.

TAYLOR, M., DLAMINI, S., MEYER-WEITZ, A., SATHIPARSAD, R., JINABHAI, V. \& ESTERHUIZEN, T. 2010. Changing sexual behaviour to reduce HIV transmission - a multi-faceted approach to HIV prevention in a rural South African setting. AIDS Care, 22(11):1395-1402.

VARGA, A. 2001. The forgotten fifty per cent: a review of sexual and reproductive health research and programs focused on boys and young men in sub-Saharan Africa. African Journal of Reproductive Health, 5(2):175-195.

VARGA, A. 2003. How gender roles influence sexual and reproductive health among South African adolescents. Studies in Family Planning, 34(3):160-172.

VERSTEEG, M. \& MURRAY, M. 2008. Condom use as part of the wider HIV prevention strategy: experiences from communities in the North West Province, South Africa. Journal of Social Aspects of HIV/AIDS, 5(2):85-93.

VICSEK, L. 2007. A scheme for analyzing the results of focus groups. International Journal of Qualitative Methods, 6(4):20-34.

WOOD, K., MAFORAH, F. \& JEWKES, R. 1998. 'He forced me to love him': putting violence on adolescent sexual health agendas. Social Science and Medicine, 47(2):233242.

WOOD, K., LAMBERT, H. \& JEWKES, R. 2008. Injuries are beyond love: physical violence in young South Africans' sexual relationships. Medical Anthropology, 27(1):43-69.

Mr Maroyi Mulumeoderhwa, Research Assistant; Prof Geoff Harris, Department of Public Management and Economics, Durban University of Technology, Durban, South Africa. 